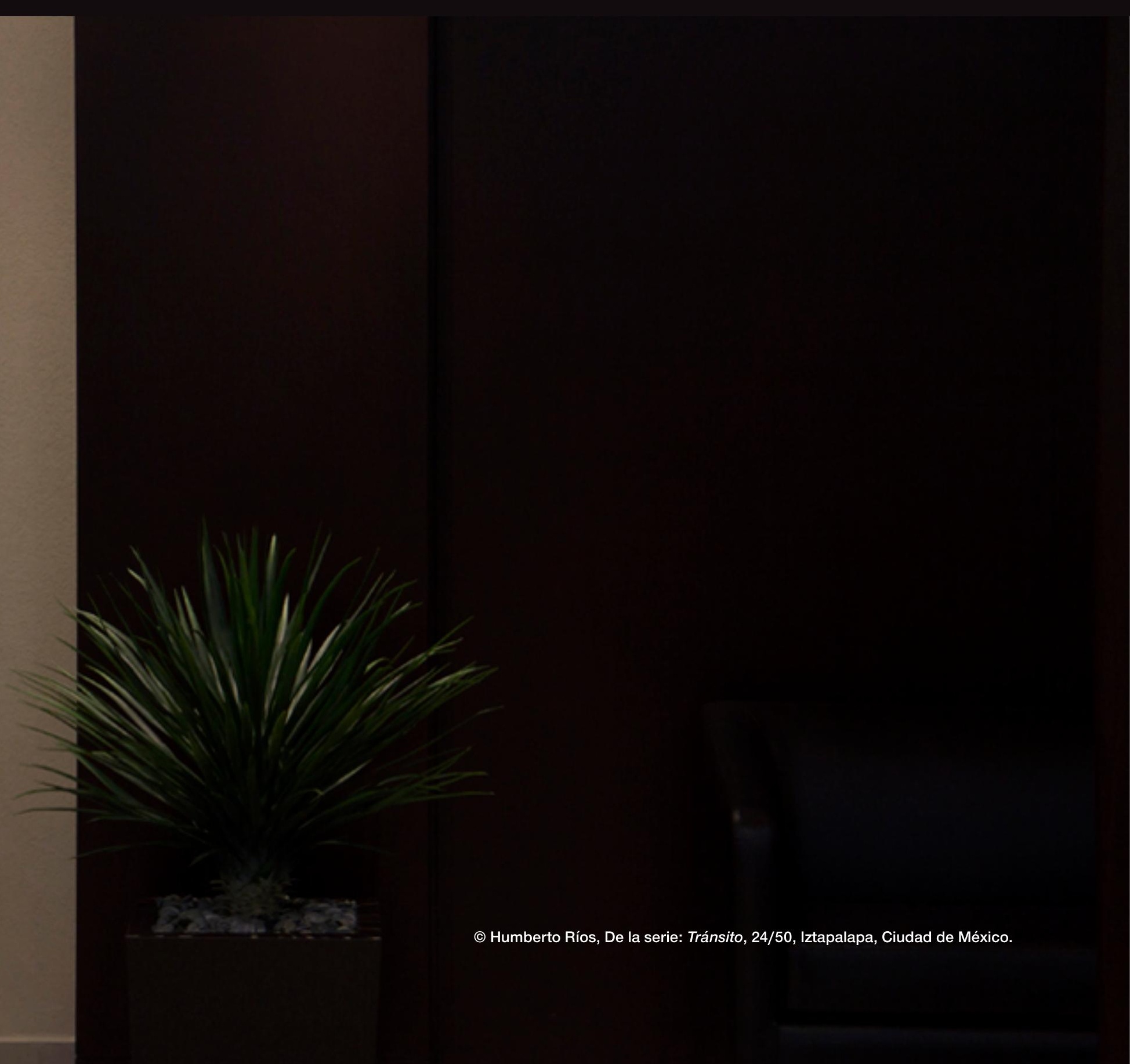




\section{De los diseños de la comunicación de los diseños}

\section{Alfonso Aguilar y Salvador Carreño}

Nowadays, the artists have a dilemma about their social function: have the creative process responsibilities around the society or not? In the field of Design this question is not feasible because the creative process have, always, a communicational function. But the principal trouble is: Designer doesn't have abilities for communication. Is very common a one false idea: Information is communication, whereas that Information is a lineal and unilateral event and Communication is co-responsible and multilateral. Is possible re-learning the communicational abilities? This article explains the pragmatist way for to design the Communication of Design.

En la actualidad los artistas enfrentan un dilema acerca de su función social: ¿tiene el proceso creativo responsabilidades con la sociedad o no? En el diseño no es posible esa pregunta, porque el proceso creativo de los diseños tiene, siempre, una función comunicacional. Pero el problema principal es que el diseñador no tiene habilidades de Comunicación. Información es comunicación y mientras que la primera es un evento lineal y unilateral, la segunda es corresponsable y multilateral. ¿Es posible reaprender las habilidades comunicacionales? Este artículo expone el camino pragmatista para diseñar la Comunicación del Diseño.

Palabras clave: Diseño; comunicación; información; pragmatismo; ética 
Discursos contemporáneos del diseño Aunque a medio siglo ya de las apocalípticas premoniciones de Jean Baudrillard y Fredric Jameson relativas a la extinción del Arte (que por otra parte se advierte tan sano como en cualquier otra época a pesar de los "esfuerzos" del maquinal, fetichista y simulacral Warhol, siempre instalado en la superficialidad de sus zapatos de polvo de diamante1, hasta su muerte en 1987), todavía se polemiza acerca de cuál debería ser la función social de los procesos creativos plásticos, de acuerdo con la perspectiva que planteaba en 1971 Roland Barthes en su De la obra al Texto: ${ }^{2}$ a) rescatar las inquietudes de una colectividad a través de la mirada del artista, para efectos del Texto dialogal, o b) identificar los sentimientos del artista, volcados en el discurso monosémico característico de la Obra.

Sea cual fuere la postura que se adopte respecto de tal dilema, llama la atención que preocupación similar se traslade del escenario de las artes visuales al propio de los diseños en sus diferentes vertientes; y resulta curioso porque, remitido al Diseño, resulta ser un falso dilema, toda vez que el discurso diseñístico se halla indefectiblemente ligado al Texto, porque ya sea que se trate del diseño gráfico, publicitario, textil, industrial o arquitectónico, está obligado al diálogo, a la polisemia y a la negociación.

Ello es así porque la Economía creativa es una de las muchas formas que adopta la comunicación humana, ese proceso siempre creativo corresponsable y dialógico que sustenta la tarea de establecer un vínculo de certidumbre entre el objeto y el sujeto, así como la cadena de interacciones comunicativas que generan la cultura, que en el camino da vida a la organización, el comercio, la moda, el entretenimiento, la política y toda socialización que nos permite usar términos como emisor, receptor, público, target, consumidor o audiencia.

Intuiciones e inspiraciones son propias de todo lenguaje; incluso no pueden faltar en lenguaje humano alguno porque la forma -el cómo de la comunicación- toma vida en la Retórica, mediante las vertientes de la seducción, la persuasión y el convencimiento, aun cuando es también en la forma del diseño donde el creativo se puede dejar llevar por el espejismo de "la musa", por el canto de esas sirenas que le susurran al oído, invitándole a dar rienda suelta a una imaginación sin cotas, de la que acaso surgirá un potencialmente exitoso ejercicio de experimentación plástica, pero que con dificultad cumplirá con la tarea comunicativa consistente en dar información al ciudadano para facilitarle la toma de decisiones. ${ }^{3}$

Así, resulta imprescindible garantizar la comunicabilidad de los diseños; diseñar la comunicación de los diseños, de forma que no únicamente se dé el vínculo entre el que oferta y el que demanda un producto diseñado, sino que ese vínculo se construya a partir de la pertinencia y la verosimilitud, del compromiso profesional y de la responsabilidad social.

Podemos advertir, entonces, que la asimilación plena de la vocación comunicativa debe acompañar al diseñador, lo mismo que al publicista, al cineasta y comunicador todo, porque el contenido alojado en el soporte - el qué del proceso- depende justo de la claridad que se tenga acerca de cómo nos comunicamos, y de la prospectiva con que construyamos cada evento, independientemente de que hablemos de comunicación comercial, entretenimiento o política.
1. Los Diamond Dust Shoes de Andy Warhol (sic) ya no nos hablan, evidentemente, con la inmediatez del calzado de Van Gogh: en realidad, casi me atrevería a decir que no nos hablan en absoluto. No hay en este cuadro nada que suponga el más mínimo lugar para el espectador; un espectador que se enfrenta a él, al doblar una esquina del pasillo de un museo o de una galería, tan fortuitamente como a un objeto natural inexplicable" (Jameson, 1990, 27). La mención de Jameson al "calzado de Van Gogh" se refiere, evidentemente, a sus "Zapatos campesinos", serie de pinturas que en su momento fueron vilipendiadas por las academias de arte, considerándolas fatuas e insulsas, mismo "pecado" que, a juicio del propio Jameson, comete el cuadro de Warhol. Consideramos poco pertinente dicho juicio, toda vez que una y otras obras pertenecen a contextos absolutamente disímbolos. No obstante, la fascinación apocalíptica que Jameson siente por Warhol puede originarse en que aquél ha pertenecido al círculo marxista de la Universidad de Duke.

2. "Lo que la Historia, nuestra Historia, nos permite hoy es solamente deslizar, variar, sobrepasar, repudiar. Al igual que la ciencia einsteniana obliga a incluir en el objeto estudiadio la relatividad de sus señales, por lo mismo la acción conjugada del marxismo, del freudismo y del estructuralismo obliga, en literatura, a relativizar las relaciones del escritor, del lector y del conservador (del crítico). Frente a la obra, noción tradicional, concebida durante mucho tiempo y todavía hoy de una forma, si se nos permite la expresión, newtoniana, se produce la exigencia de un objeto nuevo, obtenido por deslizamiento o derribo de las categorías anteriores. Este objeto es el Texto" (Barthes, 1971, p.1).
Podemos sintetizar, respecto de esta idea de Barthes, que su noción de obra identifica los procesos creativos realizados a instancias de la inspiración virgen, movidos por una fuerza inspiracional en cional e inmediato en el significante, por lo que debe ser asumido por completo como signo informativo y monista en el significado, en tanto que en la misma concepción, el texto es forzosamente diseñado, extrovertido, atemporal y plural en el significante, de manera que provoca la volición del espectador en el significado, merced a su vocación comunicativa, transmutable e intertextual. 3. Para los sociólogos críticos (recomendamos consultar bibliografía relativa a la Escuela de Frankfurt y de algunos de sus principales representantes, como Adorno, Marcuse y Habermas, entre otros), parece claro que, una vez asentado el concepto de "cultura de masas", la función inherente a los medios masivos es la de poner al alcance de toda comunidad los bienes informativos. De esto, y como un lugar común en la formación disciplinaria de la Comunicación es que asociamos esta labor natural a la toma de decisiones. Hipotéticamente, la exposición a la información proporcionada por los distintos medios facilitaría al ciudadano la toma de decisiones, ya sea que se trate de decisiones políticas, educativas, de consumo o de entretenimiento. A partir de dicho presupuesto, sin embargo, Umberto Eco refiere la división de los investigadores al respecto en Apocalípticos e Integrados, de acuerdo con la relación causa-efecto de la operación de los medios sobre las audiencias (Eco, 1965, p. 25) 
Nada de esto debería resultar extraño en los distintos ámbitos de la economía creativa; la conciencia de que la armonía entre el qué comunicar y el cómo hacerlo produce indefectiblemente un por qué o para qué, debería ser la columna vertebral de todo proyecto, de toda campaña, como un ejemplo de estabilidad y autoridad profesional.

Paradójicamente, la ejecución práctica del diseño suele evidenciar fallas sistémicas profundas en el manejo del lenguaje verbal, lo cual de suyo fisura el potencial de efectividad en el acercamiento con el perceptor comunicacional, y los esfuerzos por resarcirnos de tales fallas han costado décadas y recursos de todo tipo, sin que hasta el momento parezca que nos acercamos a un punto de equilibrio entre el discurso de la visualidad y su traducción verbal.

Pero aún más delicado parece ser el desconocimiento de la estructura sobre la que se monta el proceso comunicativo como tal, porque sigue siendo una mayoría la que se manifiesta conforme con la idea de que el proceso de comunicación consiste en que un emisor le transmita un mensaje a un receptor, sintetizando el esquema que Claude Shannon y Warren Weaver ofrecieran en los primeros años del siglo XX para explicar la forma en que se debía operar la transmisión de datos telefónicos; es decir, para explicar un proceso mecánico fundamental en la teoría de sistemas para una lógica de Información. Pero resulta que los seres humanos, al interactuar con el Mundo y entre nosotros mismos, participamos de un constructo extraordinariamente más complejo que el de la Información, palabra ésta que con frecuencia se equipara a la de Comunicación, siendo que la primera explica, desde su etimología, que consiste en encriptar datos, mientras la segunda consiste en la búsqueda de elementos comunes entre los participantes de un evento interactivo.

Con esta primera diferencia, radical en cualquier sentido, observamos que, en todo caso, una tercera palabra con la cual

4. En el contexto de la economía creativa, la declinación del término Diseñador es aplicable evidentemente a lo gráfico, lo textil, lo arquitectónico, lo publicitario o lo industrial, y es en tal contexto que aquellos quienes se ostentasen con ese título se asumen con la autoridad profesional para imponer a la sociedad el conjunto de objetos concretos reales investidos como signos que, además de consolidar el proceso de comunicación humana, sientan las bases de la moda, el estilo, la corriente y la doctrina que corresponda. Así, no es término menor ni que deba verse de soslayo, pues además de un muy riguroso proceso de planeación, desarrollo e implementación, su implante debe observarse directamente ligado al devenir cultural (por eso se emplea el prefijo "di", que significa dos -o máscaminos posibles, competitivos entre sí y destinados, los menos, a convertirse en paradigmas).

5. La corriente que equivale en Europa a la Semiótica -la Semiología-, tiene en Roland Barthes a uno de sus autores más claros; éste, así, inicia con la concepción saussureana del constructo del Signo, como el resultado de sumar una forma material -el significante- a una imagen o construcción mental -significado-, pero a partir de ello, muestra un interesante desagregamiento del proceso cuando incorpora su idea del escalonamiento sígnico, para referirse a los diferentes grados de apropiación de la realidad, obteniendo así los tres tipos de relaciones del signo: la relación interior, como proceso elemental de investidura de una forma material para que funcionen como signo; la relación paradigmática, que dota de sentido al signo en un contexto determinado, y la relación sintagmática, responsable de incorporar el contenido a cualquier forma de trama sígnica, para una argumentación. Es fácil comprender la lógica del constructo sígnico barthesiano, pero resulta imprescindible señalar la limitación que muestra para ejecutar un análisis semiótico profundo, por lo menos en contraste con el potencial peirciano.

El Pragmatismo, por su parte, se configura con una estructura de nueve categorías sígnicas esenciales, a partir de las cuales se construye un intrincado sistema de correlatos concebidos para diferenciar la multiplicidad del proceso sígnico a través de los diversos objetos concretos reales que hubieren sido investidos como signos en un contexto determinado. podríamos buscar afinidad para ilustrar la comunicación es Negociación, por la vocación de actividad y la necesidad de multilateralidad.

Comprender los pormenores de una negociación comunicacional nos deberá conducir a entender plenamente la forma en que debe diseñarse la comunicabilidad en el diseño, para lo cual sería más que útil abrevar de una disciplina (la Semiótica) que, añeja ya en los planes de estudio, o es simplificada por efecto de utilizar la equivocada vertiente de la semiología saussureana por efecto de sus preferencias lingüísticas, o se esconde en el curriculum al pensar que su profundidad resulta demasiada para los haceres "sencillos y directos" de un diseñador". Sin embargo, no es la aplicación de la semiótica en el diseño la que ocupa este artículo, como lo es, en cambio, la referencia a la teoría del conocimiento que le dio forma al estudio de los signos ${ }^{5}$ en Norteamérica: el Pragmatismo.

\section{Una visión pragmatista}

Ser pragmatista no es vocación de las culturas iberoamericanas. Desde luego, nos referimos al pragmatismo como esa corriente filosófica sustentada en las intuiciones teóricas de Charles Sanders Peirce, pero diversificada en modo tal que se ha desdibujado al grado de ser mal vista y estereotipada en su extremo utilitarista, según refiere Ángel Manuel Faerna en el texto que referimos al final del artículo.

El pragmatismo, en nuestra perspectiva ${ }^{6}$, constituye una visión teórica y metodológica aplicable a cualquier manifestación de la cultura humana a través de sus composiciones triádicas y tricotómicas, a partir de la tríada matricial que integra lo pragmático (lo remitido directamente a la realidad, los hechos, lo físico, lo vivencial), lo sintáctico (lo referido a las reglas, las normas, los códigos, el orden) y lo semántico (concerniente a la razón, el juicio, el sentido y la interpretación).

6. "El Pragmatismo - uno de los marcos teóricos más vivos y fecundos en el panorama actual de una gran variedad de disciplinas- fue un estilo de pensamiento originado... en la obra de dos clásicos norteamericanos, Charles Sanders Peirce y William James. En palabras de H. S. Thayer, el pragmatismo 'ayudó a perfilar la moderna concepción de la filosofia como una forma de investigar problemas y de clarificar la comunicación, antes que como un sistema fijo de respuestas últimas y de grandes verdades'. Hoy es una referencia principal para lo que se ha dado en llamar 'filosofía posanalítica', y también uno de los terrenos de diálogo en el reciente acercamiento entre las tradiciones anglosajona y continental...". (Editores de Introducción a la teoría pragmatista del conocimiento, cuarta de forros. Faerna: 1996).

Según los propios Peirce y James, los orígenes del Pragmatismo hay que buscarlos en el pensamiento de Sócrates y Aristóteles, en Berkeley y Hume. James reconoce también como precursor a Shadworth Hodgson, quien insiste en que "las cosas reales son sólo en tanto que conocidas". Kant, en Fundamentos para una metafísica de las costumbres, utiliza la palabra "pragmático" para caracterizar los consejos de la prudencia, como complementarios de las reglas de la inteligencia y los imperativos de la moralidad. Este principio de la razón práctica constituye por sí una anticipación al Pragmatismo. (Runes: 1981, 299).

Nosotros estamos convencidos de que todo aquél que se asuma pragmatista puede asumir, de hecho, compromisos diferentes, pues lo que consolida la corriente es precisamente la versatilidad, la diversificación de intereses, incluyendo, obviamente, lo de naturaleza diseñística. Nos parece fundamental señalar, por todo lo referido hasta este punto, que no es nuestro propósito, ni ninguno cercano, el explicar de nueva cuenta las ideas de Charles Sanders Peirce sobre estos tópicos, sino el proponer nuestra propia lectura relativa al pragmatismo. Ello explicaría, a nuestro juicio, las limitadas referencias a escritos de Peirce que algunos podrían echar de menos. 
Entendemos como tríada un constructo tripartita integrado por nociones que, asociadas, equivalen a un conocimiento disciplinario, en tanto una tricotomía es un constructo tripartita cuyos elementos equivalen a uno solo de los elementos triádicos; es decir, que una tríada da cobijo a tres tricotomías. La alfabetidad pragmatista, así, se constituye por sólo tres elementos (pragmático, sintáctico y semántico), pero la reproducibilidad hacia lo mayor y lo menor no tiene un límite aparente, pues una tríada podría ser un elemento de algo que podríamos llamar "súper tríada", en tanto que una tricotomía puede alojar tres "mini tríadas". No obstante, por simplicidad no usamos más términos que los dos iniciales, correspondiendo el término tríada al constructo mayor en el contexto que ocupe cada investigación o proceso.

El pragmatismo puede de este modo analizar procesos tan complejos como el publicitario, que indefectiblemente se conforma por tres etapas (mercadotecnia, diseño y comunicación), nueve fases y 81 tiempos, lo cual, por otra parte, coincide con lo que suele llamarse "la Z de la Publicidad", concepto derivado a su vez de la Teoría Z (Ouchi, 1981).

Con las tríadas y tricotomías podemos entonces explicarnos la armonía con que se desenvuelven procesos como el económico (producción, distribución, consumo), el sistémico (hardware, software, aplicaciones), el educativo (realidad, aprendizaje, conocimiento), el de apreciación artística (belleza, estética, arte), el teológico (divinidad, profetas, ritos), el de proyectos emprendedores (planeación, desarrollo, implementación), el publicitario (mercadotecnia, diseño, comunicación) o el de la reflexión moral y la impartición de justicia (hecho, norma, juicio), por citar solamente algunos de los procesos triádicos que con mayor contundencia exhiben el punto de vista pragmatista.

La lectura pragmatista nos ayuda igualmente a visualizar de manera extraordinariamente sencilla (con una sencillez de la que ha sido incapaz la instrucción básica típica, meramente mnemotécnica y acumulativa) la lógica estructural de construcciones tricotómicas que, no por aparentemente pequeñas son menos importantes para lograr una adecuada comunicabilidad, como la tricotomía de los acentos en español: prosódico -pragmático porque siendo el acento de la oralidad, depende de la respiración-, ortográfico - sintáctico porque al ser el acento regulado por la gramática para la escritura se aplica con base en reglas-y diacrítico - semántico porque las palabras escritas que lo exhiben, lo llevan por efecto del juicio que inscribe tales palabras en un contexto específico, al margen de las reglas del ortográfico. Observamos también otras construcciones tricotómicas tan propias de las economías creativas como misión-visión-valores, equivalentes a "qué hago", "cómo hago lo que hago" y "por qué hago como hago lo que hago", y encodificación-código-decodificación o la muy filosófica que vincula ser-saber hacer-saber ser.

De este modo, llegamos a los tópicos de interés central en esta ocasión, que son los que han de servirnos para dar una lectura pragmatista (triádico-tricotómica) al proceso mismo de la Comunicación.

\section{La Comunicación desde una libre perspectiva pragmatista}

Daremos inicio con los dos elementos que constituyen las precondiciones para que haya Comunicación. La primera de tales precondiciones es elcontexto (tiempo, espacio y noción), ya que todo lo que se comunica depende de cuándo se comunica, dónde se comunica y las circunstancias en las que se comunica.

El tiempo es el elemento pragmático del contexto, toda vez que nos hacemos conscientes de su existencia conforme transcurre nuestra propia existencia; el espacio, por su parte, es el elemento sintáctico en tanto se legisla, se norma y se regula su aprovechamiento; ${ }^{7}$ las circunstancias, en tercer lugar, son el elemento semántico al depender del juicio y las funciones del lenguaje ${ }^{8}$ que ocupan a la comunicación.

La segunda precondición es la Empatía (natural, artificial y mediática). Descrita en términos generales como "ponerse en los zapatos del otro", buscando mayor precisión anotemos que se refiere a la buena disposición para establecer un vínculo comunicativo, porque lo contrario, la indisposición, con gran probabilidad hará abortar cualquier intento de acercarnos al otro; implica el reconocimiento de la otredad, de la alteridad.

La empatía que denominamos natural (que no por llamarse así será necesariamente legítima, aunque en principio supondríamos que lo es) resulta la de características pragmáticas, porque se manifiesta en los eventos interpersonales que describiremos adelante, mientras que la empatía artificial (con potencial de legitimidad independientemente de su nombre, que no habrá que confundir con lo artificioso) muestra una naturaleza sintáctica en
7. Para profundizar en las nociones de tiempo y espacio resultaría recomendable para el lector acercarse a los texto de Paul Virilio y Marc Augé referidos en la bibliografía.

8. En Una propuesta para un modelo de comunicación, que mostramos en La comuniación no se crea ni se destruye... se habla de las funciones sustantivas: "La Función Fática, que se deriva del latín factum (hecho), como atribución del canal, tiene la responsabilidad de mantener abierto precisamente el canal. Para ello se vale de un mecanismo que se finca en los valores y principios de relación social, como la proxémica y la paraverbalidad. La forma de saludar, usar la expresión corporal o el tipo de construcciones lingüísticas que se emplean en una comunidad, constituyen parte del bagaje fático de la comunicación; a mayor aceptación de las fórmulas mínimas de interacción, mayor garantía de canales abiertos (...) La Función de Anclaje es la que utiliza el medio para asegurarse la atención del interlocutor; es del medio porque es la naturaleza del mismo la que regula el tipo de anclajes que se requiere (...) Finalmente, tenemos una de las funciones más enigmáticas del proceso, la Metalingüística, responsable de todo tipo de matices secundarios o paralelos, intencionales o incidentales que dan a la información la posibilidad de añadir un número indeterminado de funciones latentes a las funciones manifiestas que pudieran considerarse..." (Carreño/Aguilar: 2011, 27) 


\section{LA COMUNICACIÓN HUMANA}
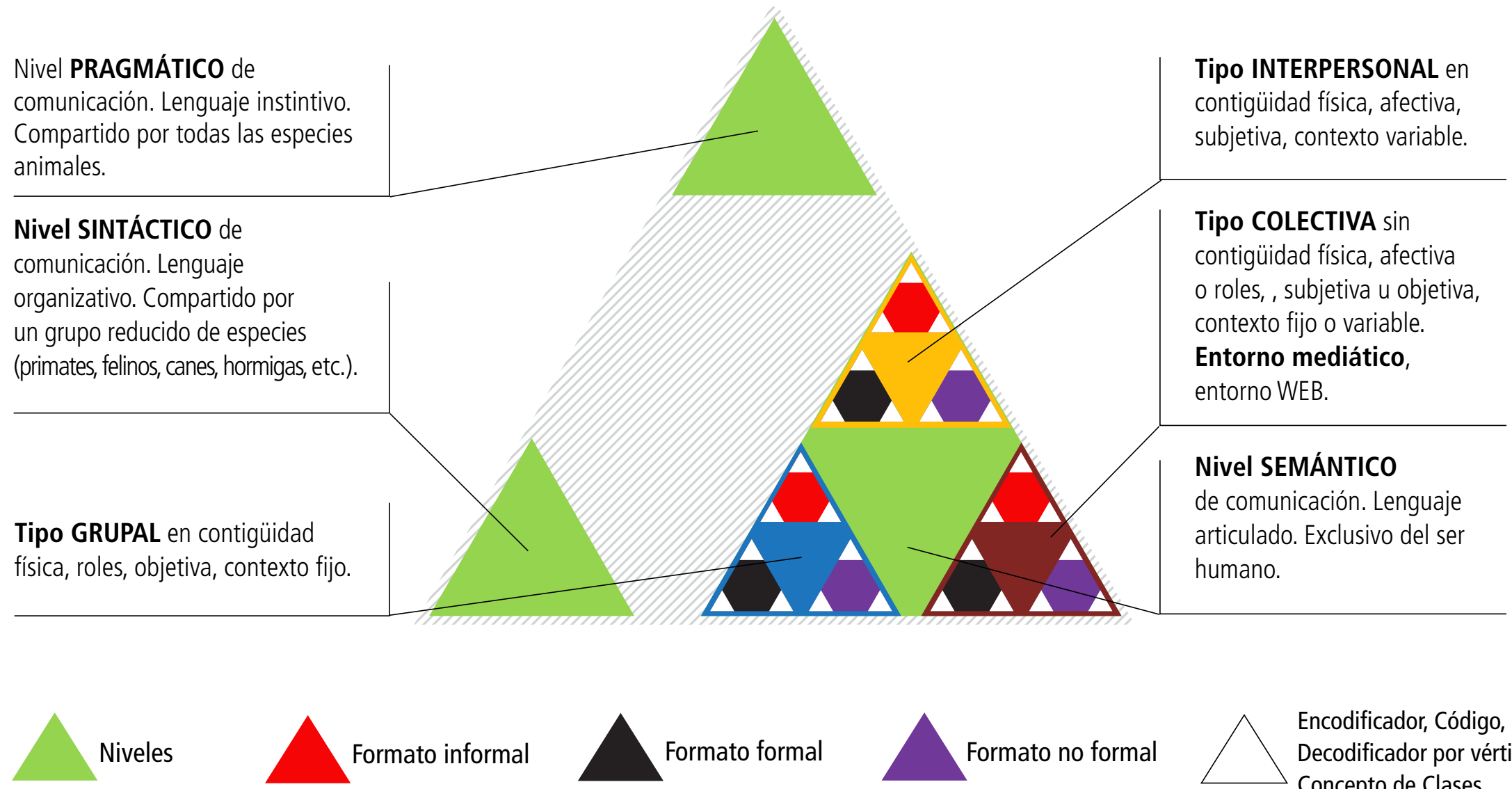

Formato forma

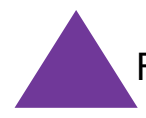

Formato no formal

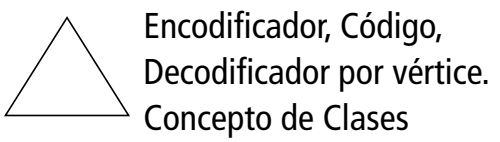

razón de que es preámbulo para los eventos protocolarios típicos de la comunicación grupal, que también describiremos en párrafos posteriores, al igual que la comunicación colectiva, bajo cuya noción se aloja la empatía mediática, que soporta los eventos que involucran tecnologías de la información y la comunicación (algunas de las que habremos de identificar con las actuales TIC) (Aguilar \& Carreño, 2014).

Así las cosas, la estructura sobre la que se instala todo evento comunicativo incluye cuatro grupos de componentes, comenzando con el grupo referido a los Niveles: pragmático, sintáctico y semántico, y que constituye la tríada (es decir, el conjunto mayor) que engloba a los componentes restantes.

El nivel pragmático de comunicación es el que se manifiesta en el empleo de los lenguajes instintivos propios de las diferentes especies animales, incluyendo al ser humano, y es en tal nivel que podemos analizar las conductas elementales como el flirteo, la violencia, las reacciones masivas frente al miedo y las emociones intensas de euforia. Parecería que estudiando la vida animal en general podríamos sacar conclusiones del nivel, comenzando con que se trata del nivel en el que el individuo busca dos cosas básicas: sobrevivir y reproducirse, pero es necesario apuntar que de la comunicación pragmática podemos hacer también observaciones de eventos peculiarmente humanos, como lo que ocurre en el futbol o en el transporte colectivo.
Por otra parte, tenemos el nivel sintáctico, el cual requiere de los posibles participantes habilidades más especializadas respecto de las que posee todo animal en lo pragmático y que sirven para procurarnos el fortalecimiento como especie, como grupo; dichas habilidades (las sintácticas) tienen que ver con herramientas útiles para mejores adaptaciones al medio ambiente, a fin de ocupar mejores posiciones en la pirámide alimenticia. Todo ello exige el reconocimiento claro de posiciones jerárquicas, además de la participación en ordenadas acciones estratégicas de grupo (de ahí su naturaleza sintáctica). Como en el nivel anterior, podríamos suponer que bastaría con estudiar la vida felina o canina, la de los caballos, las hormigas o las abejas, pero lo humano tiene también lo suyo muy suyo en este nivel, como para comprender mejor la ocurrencia de actos de relevante significado cultural observables durante siniestros naturales y tragedias bélicas, cuando el heroísmo y la solidaridad se hacen patentes.

En tercer término tenemos la comunicación de nivel semántico, circunscrita al espectro de lo humano en razón del requerimiento del lenguaje articulado, que por articulado es también reflexivo, y cuyo efecto portentoso es el de la comunicación infinita, relatora, productora de filosofía, ciencia, humanismo, arte y tecnología... aunque también de manipulación, explotación y guerra; es decir, se trata del nivel que nos permite preguntarnos por la educación, por la cultura. 
El segundo grupo de componentes, al que denominamos Tipos de comunicación, es una tricotomía ubicada en el nivel semántico (nos referimos, por supuesto, al grupo de componentes que acabamos de explicar), significando esto que se refiere a comunicación exclusivamente humana. En la dimensión pragmática tendremos entonces el tipo llamado comunicación interpersonal, mientras en la dimensión sintáctica hallaremos la comunicación grupal, y en la semántica la comunicación colectiva.

Es prudente, aquí, hacer una pausa para evidenciar tres absurdos cotidianos relacionados con los tipos comunicativos. El primero tiene que ver con la falsa idea de que las nociones respectivas pueden abordarse en términos numéricos; esto es, que un evento no será de un tipo u otro en función de la cantidad de participantes, pues en los tres habrá dos o más interlocutores, y el más puede significar muchas personas, tantas como para hablar de una comunicación masiva.

El segundo absurdo se deriva justamente de lo "masivo", porque habiendo aclarado la impertinencia cuantitativa para explicar un tipo comunicativo, podemos inferir que es igualmente impertinente establecer sinonimia entre masivo y colectivo. De esa manera, mientras una reunión familiar en la que una anciana cumpliese, por ejemplo, 100 años, reuniendo por ese motivo a su hijos y descendencia extendida, incluyendo familiares políticos, se podría reunir una verdadera masa, pero en lo masivo del evento seguiríamos viendo una comunicación interpersonal; simultáneamente, una navegación en internet, con un hablante y un oyente será, por definición, un evento de comunicación colectiva, pero de ningún modo masiva.

El tercer absurdo guarda, asimismo, relación con la cuestión numérica, pues se advierte que hemos señalado que los eventos comunicativos se dan entre dos interlocutores o más; sin embargo, es frecuente la referencia a un término inventado por los psicólogos: la comunicación intrapersonal. Si se lo ve con la frialdad de la etimología, nos daremos cuenta de que es sencillamente absurdo, pues "común" atañe a por lo menos dos, mientras "intrapersonal" acota situaciones que ocurren en la propia persona. Eso que puede ser la introspección no es, por definición, un proceso de comunicación, con independencia de que los hechos que pretende mostrar se utilicen para un evento comunicativo; en todo caso, también la Información se usa en la comunicación, pero nunca serán lo mismo.
Entonces, y para entrar en materia, definamos la comunicación interpersonal como el evento práctico, cotidiano, en el que los interlocutores participan de forma espontánea y subjetiva, sin limitaciones de tiempo, espacio o circunstancias; donde se ponen en juego los afectos. Resulta evidente que hablamos de la relación propia del ambiente familiar, con amigos, con conocidos -y aun desconocidos en encuentros casuales-, los cuales pueden ser dos o muchos.

La comunicación grupal, en lo sintáctico, deja en claro la necesidad de eventos comunicativos regulados por contratos, con objetivos y roles ajustados a tareas, tanto como se ajustan en relación con el tiempo, el espacio y las circunstancias. Se obvia así que con este tipo estudiaremos la comunicación en el ambiente académico, profesional y contractual en todo ambiente. Desde luego, este tipo de comunicación se da lo mismo entre dos interlocutores que entre multitudes. Es fácil advertir que estos dos tipos se muestran como opuestos, si bien resultan absolutamente complementarios, sobre todo porque comparten una condición: la contigüidad física. ${ }^{9}$

Y es la contigüidad física, mejor dicho su ausencia, la que se erige como característica inicial del tercer tipo de comunicación, la colectiva, definida precisamente en razón de la necesidad de suplir la contigüidad física de los interlocutores, cara a cara, con alguna especie de tecnología de la información, ya sea que se trate de algún artilugio posmoderno o una simple señal de humo; una tecnología accesible únicamente al ingenio humano. La comunicación colectiva suele reunir multitudes, pero no deja de ser colectiva si en un evento específico concurren solamente dos interlocutores, como en una conversación telefónica. Es colectiva no porque "todos" participen, sino porque en potencia es para todos. La naturaleza de este tipo comunicacional la obligan a la complementariedad con los tipos anteriores, de modo que hallaremos eventos subjetivos u objetivos, espontáneos o programados, afectivos o con roles rígidos, ajustados o no al contexto temporal, espacial o circunstancial.

Todo ello, que aquí nos ocupa unas cuantas líneas, constituye el soporte primordial de la comunicación humana, en toda su complejidad, y acaso por lo mismo quedemos en inaudita deuda con el lector, pero no es para menos si consideramos que la discusión de esta naturaleza podría abarcar no menos de un curso completo de teoría de la comunicación.
9. Respecto de la contigüidad física, conviene precisar que algunos autores se refieren a la misma como comunicación presencial o como comunicación directa. A nosotros nos parece de mayor prudencia hablar de contigüidad física, porque implica la proximidad indiscutible entre los cuerpos, o dicho de otro modo, que los interlocutores comparten el momento y el espacio físico, a la vez que sus respectivas circunstancias se cruzan por evento. En contraste, la idea de la presencialidad no se niega en los escenarios de la comunicación a distancia, generando una ambigüedad para efectos de explicar la comunicación colectiva. Así ocurre también con la noción de comunicación directa, porque las acepciones posibles podrían explicar todo tipo de comunicación. A guisa de ejemplo de lo que estamos advirtiendo, tomamos la siguiente noción de wikipedia: "La comunicación directa es el modo de comunicación humana, que se da mediante una lengua natural (ya sea éste -sic- oral o signada) y que está caracterizada por la inmediatez temporal. En la comunicación directa la producción del mensaje por parte del emisor y la comprensión del mismo por parte del receptor es simultánea y se produce mediante la relación interpersonal. Esas condiciones le dan a los mensaje una estructura discursiva especial que se contrapone a otras formas de comunicación humana como la comunicación escrita o la comunicación no verbal" (es.wikipedia.org/wiki/Comunicación_directa). 


\section{ACTANTES \\ MEDIADOR - PERCEPTOR}

ILUMINADOR - ILUMINADO

MAESTRO - ALUMNO
FACILITADOR - CONSUMIDOR

ENSEÑANTE - APRENDIZ

ALIENADOR - ALIENABLE
CAPACITADOR - CAPACITABLE

INSTRUCTOR - SEGUIDOR

HABLANTE - OYENTE
CONDUCTO - MASA

EDUCADOR - EDUCANDO
EJECUTANTE- AUDIENCIA
Pero hay más, ya que en un nuevo corte tricotómico, encontraremos el tercer grupo de componentes comunicativos, denominado Formatos (lo informal en lo pragmático, lo formal en lo sintáctico, y lo no formal en lo semántico), cuya incorporación física será la de una tricotomía repetida en los tres tipos comunicacionales, derivando en nueve escenarios particulares:

a) Comunicación interpersonal informal, como podría ilustrarse con una conversación casual entre novios o amigos, porque no implica ninguna suerte de protocolo más allá de la urbanidad de moda.

b) Comunicación interpersonal formal, donde se observa algún estatuto protocolario y/o legal, como sería un acuerdo de roles de operación y quehaceres en el ámbito familiar.

c) Comunicación interpersonal no formal, en la que el ciertamente paradójico concepto de la no formalidad no va investido de oposición a ninguno de los formatos precedentes, sino de hibridación entre los mismos, y que se explica por efecto de que en el evento correspondiente alguno de los interlocutores participa en lo casuístico de la informalidad, en tanto el otro lo hace desde la perspectiva formal. Un ejemplo apropiado sería una conversación entre el habitante de una casa que atiende el llamado de algún vendedor de puerta en puerta; el residente se desempeña en su cotidianeidad, mientras el vendedor se asume en tiempo, espacio y circunstancia laborales.

d) Comunicación grupal informal, como una convivencia festiva en el ámbito laboral, digamos un cumpleaños o una fiesta nacional, así como bromas en el contexto académico.

e) Comunicación grupal formal -lo sintáctico de lo sintáctico-, que refiere un evento rígido, protocolario como alguna junta de directorio, conferencias, conciertos de música académica, la ópera y los negocios entre colegas, clientes y proveedores, pasarelas de diseño de moda de alta costura o presentaciones de productos del diseño industrial. f) Comunicación grupal no formal, cuando por ejemplo se convoca a una presentación de productos en una aparentemente espontánea reunión de vecinos en algún condominio o conjunto de viviendas, habiendo desde luego una conducción por parte del ofertante de cremas, herramientas domésticas o moldes de cocina, y donde el sitio de encuentro queda investido momentáneamente como recinto de la marca o producto.

g) Comunicación colectiva interpersonal informal, como una conversación privada (en inbox) entre dos amigos de Facebook.

h) Comunicación colectiva grupal formal, como los sistemas de educación a distancia, bajo contrato, con derechos y obligaciones para los participantes.

i) Comunicación colectiva no formal, que responde a la noción típica de comunicación mediática, como la programación televisiva o radiofónica, la comunicación visual del diseño, los eventos cinematográficos, conciertos populares callejeros con el uso de tecnologías digitales aditivas, como pantallas panorámicas, etc.

La riqueza de la obra comunicativa humana nos invita ciertamente a buscar combinaciones de tipos y formatos en cantidades indeterminadas, lo cual devendría en muchos ejemplos, imposibles de trabajar en este espacio, pero no absurdo si, habiendo la necesidad de hallar casos específicos, seguimos el orden de división tricotómica.

Una evidencia más de la mencionada riqueza comunicacional humana la podemos ver en el cuarto y último grupo de componentes, concentrado en la noción de Clases de comunicación, incluyendo en la misma lo relativo a lo verbal, lo no verbal, lo visual y lo paraverbal, división inexacta desde el momento en que parte de un paradigma de predominio lingüístico, pero necesario de momento a falta de uno mejor, que haga patente la igualdad de los diferentes lenguajes humanos, que serán más o menos importantes en relación con el contexto en el cual sean utilizados. Dichos lenguajes, asociados por supuesto a las posibilidades sensorio expresivas del ser humano, son todos ellos lenguajes 


\section{COMUNICACIÓN INTERPERSONAL}

FUENTE FAMILIAR

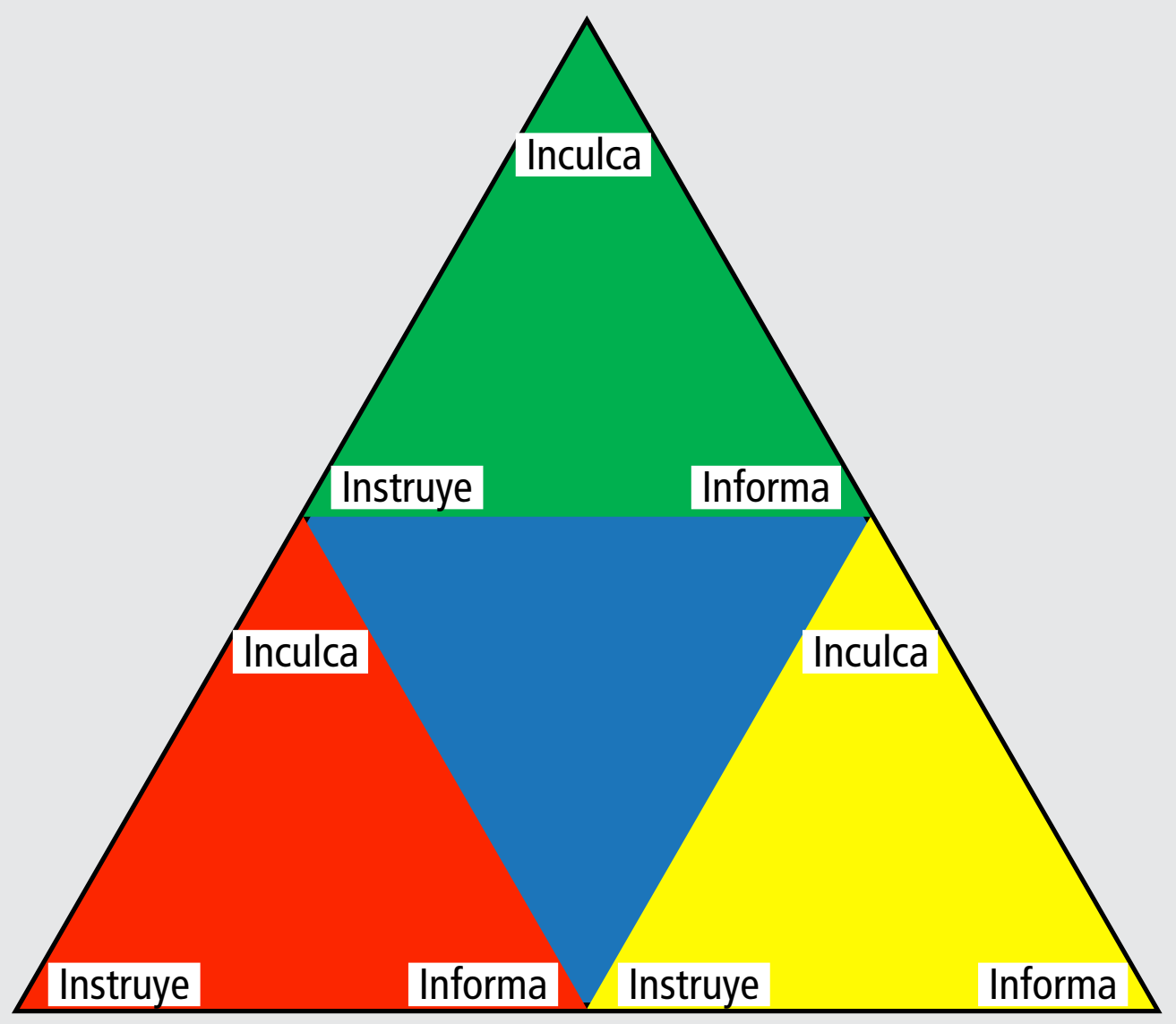

\section{COMUNICACIÓN GRUPAL} FUENTE ACADÉMICA-LABORAL

COMUNICACIÓN COLECTIVA FUENTE MEDIÁTICA

Para la construcción del individuo como líder, esto es, como un sujeto que busca el bien común y un tomador de decisiones ejecutivas en el ámbito de los negocios, antes debe tener identificadas las fuentes privilegiadas de asimilación de información, porque del equilibrio entre ellas dependerá la calidad del desempeño del individuo: La Familia: que pragmáticamente inculca costumbres, normas y valores. Las Instituciones, mismas que sintácticamente instruyen acerca de tales costumbres, normas y valores, y Los Medios de Comunicación, cuya semántica tarea es la de informar sobre todo ello.

articulados, pues evolucionan y tienen una propia retórica; o sea, que más allá de la evidencia de la articulación en el habla, por oposición al ladrido, el mugido, el gruñido o el barritado, tenemos que cualquier lenguaje humano se articula: "danzan" las abejas y danzan los humanos, pero las abejas danzan de forma mecánica porque deben hacerlo, y los humanos danzamos porque queremos, modificando nuestra danza y documentándola. Ello ocurre con todos nuestros lenguajes, ciertamente.

La comunicación verbal es la manifiesta, desde luego, en el habla y la escritura. La comunicación no verbal representa en realidad al conjunto más vasto de lenguajes humanos cuyos signos resultan ajenos y/o independientes en cuanto al signo lingüístico, como los lenguajes sónicos (la música), los táctiles, los gustativos y los olfativos. La comunicación visual, que es tan no verbal como las anteriores, resulta tan compleja e importante que se estudia aparte, y sus elementos constitutivos comprenden las Artes Visuales y el Diseño en todas sus vertientes.
Debemos hacer énfasis en la clase paraverbal, a fin de acotar que se refiere a los lenguajes híbridos (de los tres anteriores), pero que no pueden ser explicados sino en tanto funciona dicha hibridación, como sería el caso de las artes escénicas, el cine y la multimedia.

Pero más que explicar con detalle cada clase, nos interesa señalar de ellas que todas responden a la lógica pragmatista en la coincidencia de una tricotomía "comodín" que mencionamos ya antes: encodificación-código-decodificación.

En efecto, lo mismo la danza que la pintura, la palabra que la música, o la cocina que el diseño industrial, la mímica y todo lenguaje en operación, la comunicación inicia en la dimensión pragmática de la encodificación, al depender de alguna herramienta física; pasa por la dimensión sintáctica del filtro implicado en el código que corresponda y se consolida en la dimensión semántica de la interpretación, del sentido producido en la decodificación. 
Puede advertirse fácilmente la asociación entre la clase y los otros componentes, en toda su riqueza y complejidad, de forma que en el esquema, lo menos que habremos de observar es la repetición de la tricotomía comodín en las 27 posiciones posibles desde el formato, pero multiplicadas en potencia por todos y cada uno de los lenguajes posibles, con lo que se sugiere que la verdadera naturaleza del modelo bidimensional que acompaña este artículo es, sin duda, tridimensional, y basta para insistir en la reflexión inicial de atender con cuidado el diseño de la comunicación de los diseños, porque verdaderamente lejos del lugar común que supone la idea de que se comunica cuando un emisor le transmite un mensaje a un receptor (idea, por otro lado, que servirá todavía por mucho tiempo para que el lego en el asunto se haga de una somera idea del proceso), quienes nos formamos en la disciplina de la comunicación, quienes vivimos de este proceso, debemos llevar como mantra la idea de que la comunicación no se crea ni se destruye, y en su permanente transformación construye lo que nos define como humanos: la cultura, de modo que toda pregunta por la cultura es una pregunta relativa a la comunicación.

\section{El potencial Ético}

Ya instalados en una sólida estructura comunicacional, podemos colocar sobre la mesa lo relativo a la licitud de los contenidos, lo concerniente a la responsabilidad con que el creativo media entre el emisor original de cada evento de comunicación colectiva -propio de las economías creativas-y el consumidor final.

La responsabilidad moral del trabajo creativo se halla bajo el escrutinio de la normatividad vigente en las distintas líneas de demarcación, pero el diseñador de la comunicación, esto es, el profesional que concebirá nuevos signos, será capaz de imprimir su sello personal si, en el ideal kantiano, se asume como "mayor de edad intelectual", y si como candidato al juicio ético toma decisiones creativas en busca del bien común.

La estructura que el pragmatismo nos permite identificar aquí, en dirección a la concurrencia posible de la Ética ${ }^{10}$ en el trabajo de las economías creativas, identifica tres líneas de demarcación, que alojan nueve variedades de normas: la Contextual, pragmática

10."... cuando hablamos de la Ética, debemos hacerlo a partir de la certidumbre de que se trata de un objeto abstracto real; esto es, que existe en esta dimensión, pero no posee un cuerpo propio, de modo que para mostrarse ante nosotros debe posesionarse del cuerpo de algún sujeto, en condiciones propicias.

"En tal sentido, podríamos decir que la Ética y la Moral tienen eso en común, toda vez que la segunda es también una entidad abstracta real, que para hacerse presente, ello debe ocurrir en el cuerpo de un sujeto en condiciones específicas. Pero la semejanza queda en ello, porque mientras la Moral resulta ser una entidad objetiva, en la que cada uno de sus rasgos se halla tipificado y explicitado por una norma semántica denominada Valor, la Ética es completamente subjetiva, en el entendido de que es el Sujeto el que la invoca cuando a efecto de una reflexión profunda -característica de la mayoría de edad intelectual (en términos kantianos)- sublima un valor y lo hace parte de su esencia como una Virtud.

"Esto es, si partimos de la idea de que la Moral forma parte del conjunto de normas que la sociedad se impone para protegerse -en tanto que tal- de potenciales eventos destructivos del exterior y del interior, la Ética, en cambio, se configura como una filosofía de las cosas morales (y legales y por cuanto alberga la tricotomía de hábitos, costumbres y tradiciones; la Legal, contundentemente sintáctica y que nos muestra su tricotomía de norma local, norma nacional y norma internacional, y la Moral, cuyo juego tricotómico toma forma en la escala de valores, agrupados personalmente como valores imprescindibles, valores importantes y valores prescindibles. No es cosa menor aclarar que, más allá del lugar común que permite al lego utilizar indiscriminadamente los términos "moral" y "ético" para referir una conducta determinada en relación con el otro, la distancia entre ambos conceptos es enorme. Tanto la moral como la ética se plantean la observación de la conducta del individuo en dirección al bien común; sin embargo, mientras la primera condiciona al individuo por efecto de la propia norma materializada en los valores, la segunda aguarda del sujeto la voluntad de actuar en propensión al bien como producto de una reflexión profunda que trasciende la norma moral.

Dicho de otro modo, en tanto la Ética es la filosofía de las cosas morales, y como tal elucubra sobre el bien común, cuestionando o reforzando la norma, según sea el caso, la moral termina siendo apenas el instrumento práctico de dicha reflexión, y lo será hasta que una nueva reflexión ponga en tela de juicio lo que hubiera sido aceptado como paradigma moral. Así, no es extraño que el candidato al juicio ético (y conviene aclarar que el sujeto será siempre un candidato, porque actuar influido por la ética no hace del sujeto de una vez y para siempre a "alguien ético", sino que ese actuar dependerá de cada ocasión, de cada dilema y de cada toma de decisiones), sea visto como fuera de contexto, como ilegal y/o como inmoral, con los riesgos que ello implica.

El reconocimiento que acerca de las normas tenga el creativo se convertirá a su vez en la mayor de las fortalezas para añadir eficiencia a un proceso que de por sí se espera eficaz.

Podemos advertir que este constructo pragmatista relativo a la norma sigue guardando un estrecho vínculo con la noción de comunicabilidad, pues desde luego fue impreso en la mente del creativo a través de un proceso de transmisión de cada tipo de norma desde tres fuentes privilegiadas -leídas igualmente en forma pragmatista-, que son la fuente familiar, la del entorno académico-laboral y la mediática, donde la primera inculca la norma, la segunda la instruye y la tercera la informa. contextuales), de manera que no se puede tipificar en preceptos de una u otra índole y conservar su "naturaleza ética", pues cuando ocurre que una reflexión profunda relativa a una toma de decisiones afecta significativamente los preceptos al punto de modificarlos, eso que en principio fue una intuición ética termina alimentando los conjuntos de normas; esto es, que el líder imagina un escenario mejor en propensión al bien común, respecto de lo que dicta la norma cuestionada, y mientras ello tiene lugar, de resultar pública la trasposición, la transgresión o la trascensión de la misma, la multitud se turba y tiende a negar o descalificar la ruptura en términos de una violación, ya sea que se perciba al "infractor" como alguien fuera de lugar, como ilegal o como inmoral.

"Cuando el Sujeto capaz de estas reflexiones invoca a la Ética, puede ocurrir que ésta concurra y elucide al líder, pero ello no significa que el hombre se haga, de una vez y para siempre, ético, sino apenas que la persona es un candidato a encontrarse con la Ética, siempre y cuando resulte pertinente, y siempre y cuando el Sujeto se encuentre en las condiciones óptimas de reflexión pragmatista; por lo que hace a los restantes momentos de su cotidianidad, la persona vuelve al estado normal de integrante de una sociedad, con las responsabilidades y facultades que le ofrece su pertenencia al grupo" (Aguilar \& Carreño, 2014). 
El lector podrá identificar naturalmente una muy cercana coincidencia entre esta tricotomía y la que antes abordamos en el apartado de los componentes de la comunicación, cuando nos referimos a los tipos, pues en efecto, la fuente familiar de información opera -en el ámbito de lo privado- en el tipo de comunicación interpersonal, mientras la fuente identificada como académico-laboral y contractual opera -en el ámbito de lo público— sobre la estructura del tipo de comunicación grupal, así como la fuente mediática lo hace -intercalando los ámbitos privado y públicoen el obvio contexto de la comunicación colectiva.

Las tres fuentes, en la lógica de su operación, se refieren a todos los tipos de norma, cada una desde la perspectiva que le corres- ponde, quedando en manos del creativo las eventuales transposición, transgresión y trascensión, pero nada de ello podría ocurrir si antes no ha consolidado, sistematizado y profesionalizado sus habilidades para la comunicación.

Tentados de excedernos en la extensión de este artículo, únicamente alcanzamos a acotar que los términos tricotómicos apenas enunciados de inculcar, instruir e informar, así como los de transponer, transgredir y trascender guardan entre sí una recurrente estructura pragmatista.

\section{Referencias}

AGUILAR, A. \& CARREÑO, S. (2014). La Comunicación y el Objeto, en: Carreño/Aguilar: La Comunicación, Recuperdo de: http:// lacomunicacion.mx/existe-el-hombre-etico/.

AUGÉ, M. (1990). Los no lugares. Margarita Mizraji, (tr.) Madrid: Gedisa.

BARTHES R. (2013). De la obra al texto. Recuperado de http:// observatoriotrac.files.wordpress.com/2013/05/02-roland-barthes-de-la-obra-al-texto.pdf.

BAUDRILLARD J. (2007). Cultura y Simulacro, Barcelona: Kairos.

(1996). El Crimen Perfecto, Barcelona: Anagrama.

(1998). La ilusión y la desilusión estéticas,

Venezuela: Monte Ávila Editores.

(2005). El complot del arte, Argentina: Amorrortu Editores. Carreño, S. \& Aguilar, A. (2011). La Comunicación no se crea ni se destruye..., México: Instituto Cultural Helénico.

(). Empatía y Comunicación, en Publica tu Obra, www.unam.mx, portal editorial.

ECO, U. (1965). Apocalípticos e Integrados, Barcelona: Lumen.
FAERNA, A.M. (1996). Introducción a la teoría pragmatista del conocimiento, Madrid: Siglo XXI.

JAMESON, F. (1990). El posmodernismo o la lógica cultural del capitalismo tardío, Duke University Press.

(1900). La deconstrucción de Expresión,

en Art in Theory, Oxford University Press: Harrison \& Wood, eds.

LIKERT R. (1967). Organización Humana: Su Gestión y Valor, Nueva York: McGraw-Hill.

LUTHANS, F. (1987). Comportamiento Organizacional, Nueva York: McGraw-Hill.McGregor.

OUCHI, W. (1981). Theory Z: How American Business Can Meet the Japanese Challenge, Nueva York: Avon Books.

PLATTS, M. (1988). La Ética a través de su historia, México: UNAM

REDDIN, W. J. (1970). Managerial Effectiviness, Nueva York: Mc. Graw-Hill.

RUNES, D. (1981). Diccionario de Filosofía, México: Grijalbo.

VIRILIO, P. (1988). Estética de la desaparición, Madrid: Anagrama. 